\title{
BMJ Open How can rural community-engaged health services planning achieve sustainable healthcare system changes?
}

\author{
Campbell Stuart Johnston (D) , ${ }^{1}$ Erika Belanger (D) , ${ }^{2}$ Krystal Wong (i) , ${ }^{3}$ \\ David Snadden (1) 4,5
}

To cite: Johnston CS, Belanger $\mathrm{E}$, Wong $\mathrm{K}$, et al. How can rural community-engaged health services planning achieve sustainable healthcare system changes? BMJ Open 2021;11:e047165. doi:10.1136/ bmjopen-2020-047165

- Prepublication history and additional supplemental material for this paper are available online. To view these files, please visit the journal online (http://dx.doi.org/10.1136/ bmjopen-2020-047165).

Received 21 November 2020 Accepted 01 October 2021

Check for updates

(C) Author(s) (or their employer(s)) 2021. Re-use permitted under CC BY-NC. No commercial re-use. See rights and permissions. Published by BMJ.

For numbered affiliations see end of article.

Correspondence to

Dr David Snadden;

david.snadden@ubc.ca

\section{ABSTRACT}

Objectives The objectives of the Rural Site Visit Project

(SV Project) were to develop a successful model for engaging all 201 communities in rural British Columbia, Canada, build relationships and gather data about community healthcare issues to help modify existing rural healthcare programs and inform government rural healthcare policy.

Design An adapted version of Boelen's health partnership model was used to identify each community's Health Care Partners: health providers, academics, policy makers, health managers, community representatives and linked sectors. Qualitative data were gathered using a semistructured interview guide. Major themes were identified through content analysis, and this information was fed back to government and interviewees in reports every 6 months.

Setting The 107 communities visited thus far have healthcare services that range from hospitals with surgical programs to remote communities with no medical services at all. The majority have access to local primary care.

Participants Participants were recruited from the Health Care Partner groups identified above using purposeful and snowball sampling.

Primary and secondary outcome measures $A$ successful process was developed to engage rural communities in identifying their healthcare priorities, while simultaneously building and strengthening relationships. The qualitative data were analysed from 185 meetings in 80 communities and shared with policy makers at governmental and community levels.

Results 36 themes have been identified and three overarching themes that interconnect all the interviews, namely Relationships, Autonomy and Change Over Time, are discussed.

Conclusion The SV Project appears to be unique in that it is physician led, prioritises relationships, engages all of the healthcare partners singly and jointly in each community, is ongoing, provides feedback to both the policy makers and all interviewees on a 6-monthly basis and, by virtue of its large scope, has the ability to produce interim reports that have helped inform system change.

\section{INTRODUCTION}

British Columba (BC), Canada, has a population of approximately 5 million. About $14 \%$ (631 $776)^{1}$ are rural citizens distributed unevenly

\section{Strengths and limitations of this study}

- This study process has adapted Boelen's health partnership model and is unique in that it is physician led, prioritises relationships, engages all of the healthcare partners singly and jointly in each community, is ongoing, provides feedback to both the policy makers and all interviewees on a 6-monthly basis.

- A successful method of engaging with rural communities and building relationships and trust across multiple stakeholder groups is described that contributed to influencing positive healthcare system changes.

- As all communities in one province are being visited, the picture of rural healthcare initiatives and challenges is highly comprehensive and therefore able to influence policy.

- One of the main limitations in this study is that because the interviewers were experienced healthcare providers, power differentials may have existed which may have introduced bias in the discussions.

- A potential limitation is the enormous amount of data to handle and analyse in a rigorous way, which was mitigated by having two full time analysts working together to ensure consistency with frequent meeting with the research team to consider and agree emerging themes.

over an area of $944738 \mathrm{~km}^{2}$. BC is geographically diverse with a broken $27000 \mathrm{~km}$ coastline and extensive mountain ranges that make for long and often dangerous travel, complicated at times by wildfires, floods, avalanches and harsh winter conditions. Access to healthcare services for rural citizens is often limited by the expansive geography, provider availability ${ }^{2}$ and transportation issues. ${ }^{3}$

Support programmes for rural physicians in $\mathrm{BC}$ are overseen by the Joint Standing Committee on Rural Issues (JSC), a committee comprised of equal numbers of provincial Ministry of Health representatives and rural physicians. The JSC manages approximately C $\$ 150 \mathrm{M}$ (2020) of funding annually 
for programmes and projects that improve healthcare delivery in rural BC (JSC Programme Booklet). Some of this work is delivered by the Rural Coordination Centre of BC (RCCbc), which is funded by the JSC to coordinate and improve rural healthcare throughout the province. The RCCbc is a networked organisation that includes many rural physicians and a small number of rural health professionals in its network.

The Rural Site Visits Project (SV Project) was initiated in 2017 by rural physicians with a proposal to the JSC who tasked the RCCbc with visiting 201 rural and Indigenous BC communities identified as eligible for rural benefits under the Rural Practice Subsidiary Agreement (RSA). The RSA is an agreement between the Government of $\mathrm{BC}$ and the Doctors of BC (a professional organisation that represents 14000 physicians, medical residents and medical students in BC).

The purpose of the SV Project was to build relationships between rural physicians, healthcare providers, health administrators, municipal leadership, First Nations leadership, first responders, academia and policy makers through listening and gathering data systematically about local successes, innovations and challenges relating to rural healthcare delivery. These data are guiding the development of JSC programmes and informing government Rural Health Care policy.

In 1978, the declaration of the Alma-Ata International Conference on Primary Health Care stated that: 'The people have the right and duty to participate individually and collectively in the planning and implementation of their health care'. ${ }^{4}$ Current trends in rural health services, however, aim to reduce infrastructure and support to achieve greater efficiencies through centralization of services. ${ }^{56}$ Small rural communities have had to be proactive in securing local health services to resist this development, ${ }^{78}$ requiring improved relationships and communication between the policy makers and communities.

Community participation has been seen as a more complete approach to health development ${ }^{9}$ leading to culturally and contextually appropriate decisions being made about rural health services. ${ }^{10}{ }^{11}$ Relationship building between stakeholders is also seen as more effective than attempting to provide a myriad of healthcare services, ${ }^{12} 13$ especially as each rural community is unique and 'one size fits all' approaches are largely ineffective. ${ }^{6} 14$ While there have been efforts by health service policy makers to align their actions with rural communities' expressed priorities, ${ }^{15}{ }^{16}$ the processes used for community engagement have received less attention ${ }^{17}$ and descriptions seldom include adequate documentation of the processes involved. ${ }^{1718}$

The community engagement literature does not show examples of rural health projects initiated and led by physicians, even though physicians have been key partners in other research on rural community-engaged health services planning. ${ }^{15}$ Much of the research on community engagement in rural health service planning has had a specific focus, for example, in improving immunisation programmes in Nigeria ${ }^{17}$ or chronic disease care in the Torres Strait Islands. ${ }^{13}$ There are some examples of research focused on community participation for broader primary care reform, for example, in the Northern Health Authority region of $\mathrm{BC}^{15}$ and the Remote Service Futures (RSF) Project in Scotland. ${ }^{1012} 16$ The former has resulted in some sustained changes to date, for example the establishment of Primary Care Nurses, improved antenatal care and regional palliative care services. ${ }^{15}$ When the RSF outcomes were reviewed in 2014: 'Only one direct sustained service change was found'. ${ }^{19}$ These raise the question of how best to achieve sustainable beneficial rural health system changes using community engagement processes. The project described here attempts to address this issue. Due to the complex nature of this initiative, it is presented in this article as two components. First, the process of engagement in terms of how communities were engaged and how information was shared with them after the visits. Second, as the data gathering and engagement process are entwined, information on the research methods and broad early results are included to provide a context for future more detailed publications arising from the data.

\section{PROCESS OF COMMUNITY ENGAGEMENT}

\section{Theoretical approach}

The Health Partnership model described by Boelen ${ }^{20}$ was used. This identifies five partners: health professionals, academic institutions, policy makers, health managers and citizens and recommends they meet together to identify ways to improve health systems. The concept of meeting with the partners in each community was modified to include additional separate meetings with each of the partners. Who constituted the health partners could be different in each community, so the concept was adapted to the local context to include those present in the community. This included First Nations and others such as first responders, business and non-profit groups. It was not possible to have combined partner meetings in all communities as it was not always possible to find a date and time within the visits time line that worked for everyone. This process in British Columbia has become known as the pentagram plus framework. This approach does not seek representation from the various groups but seeks perspectives from those who are part of a group.

\section{Patient and public involvement}

Public input into the project occurred during the initial pilot Site Visits to eight rural communities and was used to shape the community engagement process and the interview guide.

The initial interview guide was developed by the investigators, who had many years of rural healthcare experience, to elicit broad discussion about multiple healthcare issues. The guide was refined based on public and provider input during pilot visits. 
Participants were asked for feedback on the interview process and whether the time taken was appropriate.

\section{Arranging site visits}

The sites identified for the SV Project were the 201 communities identified under the RSA.

Sites are selected 6-12 months in advance. Three to 6 months prior to a Site Visit, recruitment of participants commences and RCCbc staff coordinate the planning. Depending on community size and location site visits last one to 3 days and involve one to five communities.

\section{Site visits team}

A Site Visits team consists of at least one Site Visitor and one RCCbc staff member, who coordinates the visits. The Site Visitors comprise 19 rural physicians and one midwife all of whom are RCCbc members and responded to a call for site visitors. A 1-day training session for visitors included training in Appreciative Inquiry techniques, qualitative interviewing and cultural safety through the San'yas Indigenous Cultural Safety Training course. Site Visitors were individually mentored by the Programme Leads on their first visits. On some Site Visits, guests are invited. The purpose of inviting a guest is to assist urban-based allies in their understanding of how healthcare functions in small rural communities. Guests have included policy makers, researchers, healthcare workers, administrators, and educators and all guests broaden the perspective of the visit team.

\section{Participant recruitment}

The visits included participants who identified themselves as living or working in a RSA community and were part of one or more of the partner groups identified by Boelen. ${ }^{20}$ Participants were initially recruited from the healthcare partner groups by:

- Email and phone contact through publicly available information.

- Recruitment posters in doctors' lounges, hospitals, clinics, and municipal buildings.

- Contacting pre-existing contacts who provide connections to potential participants.

- Asking participants to suggest others who fit the inclusion criteria.

Initial contact was made by telephone or email to members of health partner groups (physicians, administrators and allied health professionals) with a follow-up invitation that detailed the project background, aims and goals and included a copy of the interview guide. The most successful method was using known contacts to identify potential participants and by asking them to pass information on to them (snowball sampling ${ }^{21}$ ). Participants were invited to participate in one-on-one interviews or focus groups (if there was more than one person from an identified health partner group) and dates established. Interviews took place in the communities; however, since March 2020, 11 virtual interviews have been trialled as a result of COVID-19 restrictions. In general, participants from community groups were local leaders such as local elected officials, leaders of non-profits or businesses. In First Nations, communities initial contacts were through community health centres. Coming from small rural communities everyone had a perspective as a community member in addition to their other roles. All participants were sent consent forms and information sheets before the visit date but not obliged to sign consent forms until the start of interviews to give time to ask questions or clarify issues. Verbal reconsent was sought at the end of interviews. Framing the process as a research project also had benefits in having ethics approval which meant comprehensive informed consent processes, confidentiality and security over data storage and handling. All of which appeared to contribute to participant trust in the process.

\section{Interview methods}

Each health partner group (between one and sixteen participants) was interviewed separately. This was followed by a combined partner focus group (between 2 and 10 people) with a representative from each of the health partner groups previously interviewed. The interviews incorporated an Appreciative Inquiry approach ${ }^{22} 23$ with public input to develop a semistructured interview guide (online supplemental file 1) that would help build relationships and lead to better understanding of how rural community members perceive healthcare delivery within their respective communities including healthcare successes, innovations and challenges that inhibit their ability to access services in an equitable manner. The guide has been iteratively refined following community visits, in keeping with standard qualitative methods

Interviews were recorded digitally and transcribed. Interviews generally lasted 1 hour. Transcripts were returned to participants within 4 weeks for verification, alteration or withdrawal if requested.

\section{Continuing engagement}

The data collected was managed through a research process to ensure rigour of the data analysis (see Data Analysis and Results section). To continue engagement with communities, emerging themes from the analysis are disseminated to all participants and communities. They are also shared with policy makers, physicians, allied health professionals, First Nations, municipality members, academics and the general public to ensure rural communities health priorities are understood. Various knowledge translation outputs are used such as 6 monthly JSC and publicly available community feedback reports and newsletters, specialised (focused) reports, presentations, briefing notes and publications. Additionally, an Innovations website has been established to share successful innovations identified by interviewees.

Full details on the site visit process are given in the Rural Site Visits Handbook (online supplemental file 2) 


\section{DATA ANALYSIS AND RESULTS \\ Data analysis}

The data source were transcribed interviews, after they had been returned and agreed by participants. To process the large volume of qualitative data collected, qualitative

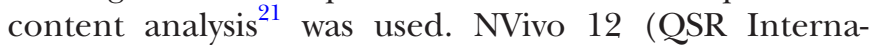
tional) was used to help organise the data. Initially, each interview was coded using an inductive-approach and primary cycle coding. ${ }^{21}$ This began with a close reading of the data, assigning words or phrases that captured the essence of each sentence. From this, a codebook was developed (online supplemental file 3), and second level codes were generated to identify emerging themes across the data. Throughout the entire analysis process, data were revisited to allow for the comparison and modification of codes to fit new incoming data.

Rigour was maintained throughout by a second data analyst. Analysts coded identical interviews separately and then compared coding to promote consistency. Analysts met weekly to discuss changes and modifications needed for the coding framework. The coding framework and emerging analysis was discussed and agreed within the research team. The data were further interpreted to identify themes connecting the data across communities. ${ }^{21}$

\section{RESULTS}

\section{Site visits engagement process}

Although the COVID-19 pandemic has significantly slowed down the project, 382 interviews have been carried out in 107 communities over a 3-year period (table 1). The communities ranged in size from small communities of approximately 200 people to communities of $10-20$ 000 people. There was one large community of 70000 , but considered remote being $800 \mathrm{~km}$ from major tertiary care services. The first 4 site visits to 9 communities with

Table 1 Partner group interviews

\section{Health providers and clinicians}

\begin{tabular}{|c|c|c|c|}
\hline Health partner group & Definition & $\begin{array}{l}\# \text { interviews } \\
\text { analysed }\end{array}$ & $\begin{array}{l}\text { \# pilot interviews } \\
\text { analysed }\end{array}$ \\
\hline Physicians & $\begin{array}{l}\text { Majority were family physicians, but also includes residents, } \\
\text { specialists, hospitalists and nurses }\end{array}$ & 52 & 6 \\
\hline Midwives* $^{*}$ & Midwives (could also include students) & 4 & 0 \\
\hline Nurse practitioners* & Nurse practitioners (could also include students) & 7 & 0 \\
\hline \multicolumn{4}{|l|}{ Health administrators } \\
\hline
\end{tabular}

First Nations/Community Members $\dagger$

\begin{tabular}{|c|c|c|c|}
\hline First Nations & $\begin{array}{l}\text { First Nations Band members, First Nations community } \\
\text { members, elders, chiefs, health directors, community health } \\
\text { representatives, nurses, health coordinators }\end{array}$ & 29 & 2 \\
\hline First Responders* & Fire chiefs, paramedics, community paramedics & 1 & 0 \\
\hline \multicolumn{4}{|l|}{ Policy makers } \\
\hline Municipal & $\begin{array}{l}\text { Mayors, councillors, regional district directors and members, } \\
\text { community members }\end{array}$ & 34 & 5 \\
\hline Academics* & $\begin{array}{l}\text { Clinical professors, clinical teachers, clinical researchers, } \\
\text { medical school professors }\end{array}$ & 2 & 0 \\
\hline \multicolumn{4}{|c|}{ Linked sectors industry and non-profit } \\
\hline Health organisations/societies & $\begin{array}{l}\text { Community members, community health advocacy groups, } \\
\text { hospital auxiliaries }\end{array}$ & 4 & 0 \\
\hline Total number of interviews & & $\begin{array}{l}185 \text { interviews } \\
\text { analysed to date } \\
\text { not including pilot } \\
\text { interviews }\end{array}$ & $\begin{array}{l}23 \text { (\# of pilot } \\
\text { interviews } \\
\text { analysed for } \\
\text { primary codebook } \\
\text { development) }\end{array}$ \\
\hline
\end{tabular}

*Additional partner groups were added later in the study.

†Community Members are embedded throughout the groups. 
23 interviews were used to pilot and develop the methods and were not included in the analysis reported here which is based on 185 interviews with 754 participants in 80 communities. The data from the remaining 27 site visits are in process of transcription, returning transcripts to participants and analysis. As the data are well saturated and as the processes take several months, it seems appropriate to report the study now.

The participants interviewed bring a wide variety of perspectives. Many health administrators are also nurses or other health professionals and they were able to bring those perspectives to the conversations. In addition, in the health partner group interviews nurses often came to those meetings accompanying physician colleagues. Across interviews collectively, one participant withdrew their transcript. Many participants provided feedback; highlighting their enjoyment of the direct, in-person engagement process that was used and the connections they provided:

'I think this has been very informative. Just getting to know what you guys do... and [the] supports (that exist) and establishing connections and...learning about these connections that exist that I haven't tapped into personally so, it's great.'-Combined Partners

Participants further described how they felt the process allowed for their voices to be heard and their communities to be recognised:

'I appreciate being able to talk... and to give frank feedback because that is tough at times and this is a good option to do it...some of our issues aren't really out there right? So, it's good to be able to have a voice to be able to indicate this.' - Nurse Practitioner

'I want to thank you for recognizing us as 'rural,' because a lot of people don't see us as rural.'-First Nations

It was commonly voiced by participants that, throughout the engagement process, they would love to learn about what other communities have achieved.

'Would love to see information about other initiatives going on around other provinces that they might be able to learn from.'-Combined Partners

'[We] would like to receive feedback about how [we] work with other communities and what works well in other communities.'-Combined Partners

These requests from participants ultimately led to the creation of the Site Visits Innovations website.

\section{Common themes}

The data have become well saturated with 36 categories emerging from the data to date. The 10 most common themes are included in online supplemental file 4 and these will be the subject of subsequent publications. This article reports three overarching themes that interconnect all the data: Relationships, Autonomy and Change Over Time.

\section{Relationships}

Relationships were important in achieving successful healthcare outcomes and were built on communication, trust, transparency and collaboration over time. These themes were evident in every community:

'It's really groups of people coming together on committees that have people from city council, the regional district, health boards, and the non-profit societies... and I think if there's a strength in this community, it's that there are those connections and people are willing to work together to find solutions locally.'-Combined Partners

Good relationships underpinned communities' abilities to successfully retain their physicians. These relationships were with the communities themselves as well as with administrators and within teams:

'Why do you think they've stayed here?'-Interviewer '[It's] the relationship that they [the physicians] maintain with the community...It all comes down to the relationships.'-Municipality

'When we went to [Health Authority X] to say, 'We're having a terrible time retaining our doctors,' - the turnover was terrible - we got no response from the system. So, the community rallied around and did what was necessary to sustain doctors in this community. But in doing that .... what we did was create relationships with our physicians that are respectful and goes [both] ways.'-Community Members

Effective communication and regular 'organic' contact were the foundation of these relationships and were important in building trust:

'Having all the different services all in the one building does allow for good open communication, you can pull anyone aside if you bump into them in the hallway to talk about patients. It is a very organic process rather than a formalized team-based care approach... It also helps retain people who work here - you build that relationship and trust of what your peers are capable of. It's not formal team-based care, but it is a team.'-Combined Partners

'There needs to be trust and consistency of knowing what someone is walking into. Issues of trust (have been) a major block in [our] community to providing and receiving health services.'-Health Admin

Successful collaborations that were inclusive of all partners positively impacted healthcare and helped reduce burnout:

'It makes it much easier working [here], because I've worked here a really long time with [colleagues $\mathrm{X}$ and $\mathrm{Y}$ ] it makes it much easier when we have a group that all works together really well. And that doesn't 
happen everywhere. [We] are all friends so [we] tend to help each other out... being [without them] ...the burnout would be terrible.'-Physicians

'It's really groups of people coming together on committees that have people from city council, the regional district, health boards, and the non-profit societies that identify the problems and look at what each particular group...can provide to try to deal with the problem and...it's those connections and people (who) are willing to work together to find solutions locally.'-Combined Partners

Conversely, poor collaboration and relationships led to adverse consequences:

'...when I meet with my doctors, I hear one thing about what the problem is and how to solve it. And then, if I talked to nurses or midwives or allied health professionals, I hear another version of what the problem is and how we would fix it. And then I sit down with [Health Authority X] and I hear their version of what the problem is and that they are fixing it. And all those voices are never in the same room at the same time...'-Municipality

Good relationships enhance problem solving, reduce the 'red tape' required to affect change and result in greater work satisfaction at all levels, positively affecting other issues such as recruitment, retention and burnout. Local decision making (autonomy) was an important contributor to work satisfaction.

\section{Autonomy}

Autonomy within the healthcare context was defined in many ways. However, at its core, many viewed autonomy as the ability to make reasonable decisions, sensitive to the local context, at a personal or local level that did not require the blessings of a hierarchical, top-down system. The latter stifled initiative, innovations and satisfaction.

A sense of autonomy within the healthcare providers appears to improve recruitment and retention. It imbued a sense of greater 'ownership' of, or responsibility for, the local services by the community practitioners:

'Part of it is the relationship that they maintain with the community...Dr $[\mathrm{X}]$ has come to the council and has asked for extra room to bring in more medical professionals, and the city worked with him so that he can have the space to have another professional help out his team. The main thing is working with them and letting them grow, not dictating to the doctors.'-Municipality

The data described a disconnect between centrally directed processes and what was practically achievable in a community:

'...I think there's kind of an issue sometimes with delivery of rural health care in that people actually in the trenches doing the job have a much better insight sometimes into what needs to be done and what is happening than the people making the decisions about how we're going to deliver the health care.'-Physicians

The most frequent plea was that more local engagement was needed to solve local problems and how important local autonomy was in crafting enduring solutions:

'I couldn't believe that-'we are bringing more resources and that's not working for you?' What didn't happen is there was no consultation, so it didn't really matter if we brought more resources. It was like, 'you didn't ask us what our problem is, what we need and what is our reality and you're just bringing resources and that's not how we want this to look like...'Health Admin

'...locally it feels like our concerns are profoundly dismissed by the health authority, who clearly have a different idea and a different agenda'... 'We need to be kind of at least a largely autonomous community.'-Physicians

When consultation occurred a very different attitude existed among the healthcare providers:

'...So, we took that learning and stepped back and took one whole year to do focus group and to follow staff to understand what they're doing, what are the challenges, the issues, to understand better the population that we serve...involving physicians along the way and after we've done all of this, we came up with another model, not really with much more budget... but it wasn't about the budget anymore and we've presented the model to the staff in March and since then, we are implementing the new model and it's working and people are just following along the process and I think that there's a lot of learning about the history of the community and how we need to do things here.'-Health Admin

Local autonomy meant the ability to make rapid operational decisions on the day. Many small rural communities had extraordinary stories of unbroken $24 / 7$ emergency coverage for many years provided by the local practitioners despite being reduced to a single physician at times. Similarly, nurses in small rural hospitals frequently did additional shifts to cover gaps when their colleagues were unable to work. These providers felt a responsibility to maintain these services in their community:

'I had a lot of autonomy about who I could hire... and so I had the ability to hire locally and so I built a big pool of people who lived here who were very committed to [the] Healthcare Centre.'-Health Admin

When control of these services was elevated to a higher level outside of the community, this loyalty was reduced as local autonomy was lost, contributing to Emergency Room coverage gaps and difficulty filling nursing shifts: 
'...So now we have one GP who is keeping the whole system going through being on call 24 hours a day, 7 days a week. So, it's sort of a step backwards, and I think a lot of it is just that we've lost the autonomy to be able to kind of say, "Well, this is what our community needs. This is how we can go about solving this problem."'-Physicians

'...you've done a really innovative thing in adjusting your nursing lines...this is the first community we have not heard [about] nursing shortages.'-Interviewer

'So, we need to start developing our rotations to make it attractive for those nurses to come...We're one of the few rural sites that have full staffing now.'Health Administrator

One example of a successful model is a 3-year trial in a region where a Health Authority granted three geographically close rural communities the autonomy to determine their priorities for improving local healthcare and provided funding to support these changes:

'We had a series of engagement events for the entire community, health care providers, public, youth at one of the high schools, our Indigenous population, and the [Community X Group] and said, where would you like to spend $\$ 500000$ on services and so 5 things came to the top...'-RCCbc Video

Autonomy as defined by the local ability to make relevant healthcare decisions, runs through all the data as a foundational theme in supporting system improvement.

\section{Change over time}

'Change over time' is a prominent contextual factor that underpins all the themes within the SV Project to date. One of the biggest changes over time has been the change in community population. Some remote and resource-based communities reported diminishing populations, however, this was much less common than those reporting increased population growth due to young families leaving cities to find affordable housing and retirees moving in. In addition, there is a growing tourism load in many communities. These factors, exacerbated by the expectations of care for those that have moved into the community, have impacted resources and funding for longstanding residents:

'...a lot of communities are struggling with what to do with a very quickly growing, aging population...we have a very strong in-migration of young families...'-Municipality

'[Our] patient population has increased... [and the] infrastructure has not changed.'-Physicians

'...communities in [Region $\mathrm{X}]$ have been shrinking since forestry work has moved [away from Region $\mathrm{X}]$.'-Municipality

Participants emphasised how demographic and population changes have created local concerns that the community services are not adapted to the changing contexts; thereby causing issues that relate to capacity, patient access, staffing, service demands, manpower and funding that do not meet the communities' needs:

'...our community is growing, like our nation is growing, but the services haven't. And so, everyone's fighting for a doc...'-First Nations

'I think we're just lacking that vision for the hospital in what is a basic level of service to serve a growing community of 21000 that also supports 2-3 communities north of us.'-Municipality

'...And trying to actually keep up from a staffing perspective, from a staff retention, everything from a budget, like it's we are playing a really hard game of catch-up because it's growing faster than we can even account for and put in services to meet the needs. That's what I think the biggest challenge is...'Health Admin

Rural communities are dynamic and, because of their size and isolation, particularly vulnerable to changes, which may not be easily anticipated. Change is continual and only those that have the ability to find ways to adapt are able to continue to deliver effective health services.

\section{DISCUSSION}

The Site Visit Project has strengths in the degree of its engagement and, after engaging with 107 rural communities and conducting 382 interviews, it has shown that it is possible to collect large volumes of data about local healthcare issues in a systematic and meaningful way in order to influence provincial health service changes. The fact that the Site Visits team travels to each community appears to have a strong influence on the relationships and trust experienced in the interviews. Many of the interviewees have informally commented on this fact, noting that they feel that the Site Visits team now understands their remoteness, available services, difficulties with transporting patients and so on and that they feel 'heard'. One limitation of this project is that it was carried out in British Columbia and supported by adequate resourcing through negotiated public funds allocated through the provincial physician organisation. This means that it is specific to the context of British Columbia but may have elements transferable to other settings. It would only be possible to replicate this project with sufficient funding supports.

The major themes are being identified and the analysed data shared as specialised reports to both the micro and macro policy maker levels. The data are used by various organisations to provide a community-provided rural perspective to discussions. For example, emergency transport was an issue raised by all rural communities apart from a very few within helicopter range of Vancouver. Site visit data were provided to a provincial partners' table convened by the RCCbc and discussion there informed 
a provincial government announcement of further rural emergency transport resources. Other examples of reports created from the data for specific issues can be found at https://rccbcca/rccbc/resources/documents/. The processes described have implications for policy makers in terms of rural health, ones that can be adapted to different contexts. System changes influenced by the visits data will be the subject of future publications.

The three themes described in this article appear as patterns throughout the data set. They are interlinked and can be seen as foundational elements for effective functioning of healthcare services in rural communities. Good relationships between providers, health authority administration, external specialist services and community members were repeatedly identified as being responsible for high functioning, successful communities. This means that effort needs to be made to create the time and space to develop relationships and that these efforts are valued by all sectors. Part of the importance of relationships was linked to the concept of autonomy which in this sense meant the ability to make local decisions when needed. Autonomy impacted the sense of well-being of the partners and could also produce very practical, rapidly implemented changes with positive results. The exercise of autonomy however can be problematic if not carried out within an agreed framework that requires the limits of decision making to be set and agreed with health service administration and which recognises historical power differences in healthcare. ${ }^{15}$ Finally, change over time is recognised as being an important contextual factor in the provision of services to small rural communities and the resilience of these communities seems related to their ability to adapt to often unexpectedly changing circumstances. Such adaptation would appear to be easier in a context of good relationships and an agreed approach to local autonomy.

There are many examples in the literature of community engagement, though the literature does not appear to contain any examples of such widespread engagement being used to support policy change at a provincial level. The SV Project benefited from the fact that it is purely about listening. It did not promise change, but rather that the information gathered would inform change. Using Boelen's Health Care Partners model at microlevels and macrolevels, ${ }^{20}$ the results of the SV Project are being used to discuss contextually appropriate changes for rural healthcare. Having all the partners present at these discussions appears to increase the chances of producing successful and sustainable outcomes. The findings fit within the 'five rules of Large System Transformation' described by Best $e t a l^{25}$ and illustrate that rural healthcare is a complex adaptive system. While this study does not attempt to explore complexity, it does offer a framework for engagement, data gathering and analysis that is sensitive to complexity and local contexts and may point to an example of the paradigm shift Greenhalgh and Papoutsi call for in their editorial on studying complexity in health services research. ${ }^{26}$

\section{Limitations}

Not all partner groups existed or were available to meet in some communities. The latter was rare and virtual meetings were arranged when necessary.

Because the Site Visits teams were led by experienced healthcare providers, a power differential existed during the interviews which may have been inhibitory, particularly when interviewing Indigenous groups.

As the interviews were led by healthcare providers it is possible that they may have biased the discussions.

The data collected is specific to the geography, health system and rural context of $\mathrm{BC}$ and may not be fully transferable to other settings.

A potential future limitation may be disengagement by the communities from further site visits if no beneficial changes are seen to occur.

\section{CONCLUSION}

By modifying Boelen's approach to partnership in health development, the SV Project has demonstrated a successful way to engage rural communities and gather extensive data that can be used to inform rural healthcare policy in an ongoing and contextually appropriate manner. Relationships, communication and relevant data are the cornerstones that successful sustainable change is built on.

While every rural community is different, this project elicited many common themes that have linked the healthcare issues in rural BC. Although early changes have already occurred, further research will be needed to determine whether the changes resulting from the SV Project are beneficial and sustainable with time.

\section{Author affiliations}

${ }^{1}$ Interior Node, Rural Coordination Centre of BC (RCCbc), Penticton, British Columbia, Canada

${ }^{2}$ Northern Node, Health Research Institute, Rural Coordination Centre of BC (RCCbc), Prince George, British Columbia, Canada

${ }^{3}$ Vancouver Node, Rural Coordination Centre of BC (RCCbc), Vancouver, British Columbia, Canada

${ }^{4}$ Family Practice, The University of British Columbia Faculty of Medicine, Vancouver, British Columbia, Canada

${ }^{5}$ Northern Medical Program, The University of British Columbia Faculty of Medicine, Prince George, British Columbia, Canada

Twitter Campbell Stuart Johnston @RCC_bc, Krystal Wong @RCC_bc and David Snadden@dsnadden

Acknowledgements We would like to thank the entire RCCbc Site Visits Project team for helping with the administrative coordination and reach out to communities throughout the duration of this work. We would also like to thank Gemma McEachern for providing key supports during the initial phases of this project and Anne Lesack for assisting with the data analysis throughout this project. We would like to further extend our thanks to Dr Martha McLeod and Jason Curran for providing us with an external review and feedback on our manuscript. Thank you to the Joint Standing Committee for funding this work and allowing us to continue this project. Most importantly, we wish to acknowledge all our participants who chose to welcome us to their communities and allowed us to listen to their experiences and perspectives. We thank you for participating in this work and contributing your voices.

Contributors All authors contributed to and agreed the final version of the article. CSJ is the project lead, has been involved in all stages of the project design, has 
attended visits and has helped with data analysis. He wrote the first draft of the article. EB is the primary analyst and developed the analytic methodology, the codebook and the initial content analysis. She has attended visits and contributed to all sections of the article. KW developed the Site Visits processes, attended visits, has been involved in all conversations in terms of the analysis and contributed to all sections of the article. DS developed the qualitative methodology and guided the research methodology, assisted with analysis and determining themes and contributed to all sections of the article including developing and editing the final version. DS is the guarantor of this work.

Funding This project is supported by funds from the Joint Standing Committee on Rural Issues through funding negotiated through the Ministry of Health and Doctors of BC's Physician Master Agreement. Those funds are administered by the Rural Coordination Centre of BC. Award/Grant number is not applicable.

Competing interests CSJ is funded as a Director of the RCCbc. EB and KW are full-time employees of the RCCbc. DS was the Inaugural Rural Doctors' University of British Columbia (UBC) Chair in Rural Health from 2016 to 2020, which is supported by an endowment to UBC from the Rural Doctors' of BC through the JSC. He also sits on the RCCbc Leadership group to provide an academic perspective. He is fully funded by the Faculty of Medicine at UBC as a Professor of Family Practice. There are no other competing interests.

\section{Patient consent for publication Not applicable.}

Ethics approval The study received harmonised ethics approval from the University of British Columbia Behavioural Research Ethics Board with Harmonised approval in Northern, Interior and Island Health Authorities and the University of Northern British Columbia. (Certificate H17-01591). Operational approval was also received from each health authority.

Provenance and peer review Not commissioned; externally peer reviewed. Data availability statement № data are available.

Supplemental material This content has been supplied by the author(s). It has not been vetted by BMJ Publishing Group Limited (BMJ) and may not have been peer-reviewed. Any opinions or recommendations discussed are solely those of the author(s) and are not endorsed by BMJ. BMJ disclaims all liability and responsibility arising from any reliance placed on the content. Where the content includes any translated material, BMJ does not warrant the accuracy and reliability of the translations (including but not limited to local regulations, clinical guidelines, terminology, drug names and drug dosages), and is not responsible for any error and/or omissions arising from translation and adaptation or otherwise.

Open access This is an open access article distributed in accordance with the Creative Commons Attribution Non Commercial (CC BY-NC 4.0) license, which permits others to distribute, remix, adapt, build upon this work non-commercially, and license their derivative works on different terms, provided the original work is properly cited, appropriate credit is given, any changes made indicated, and the use is non-commercial. See: http://creativecommons.org/licenses/by-nc/4.0/.

Author note Reflective statements on author perspectives are available as online supplementary file 5 .

\section{ORCID iDs}

Campbell Stuart Johnston http://orcid.org/0000-0001-9697-7665

Erika Belanger http://orcid.org/0000-0002-2511-8799

Krystal Wong http://orcid.org/0000-0002-3151-785X

David Snadden http://orcid.org/0000-0002-4818-1184

\section{REFERENCES}

1 Population and Dwelling count highlight tables, 2016 census Ottawa: statistics Canada, 2016. Available: https://www12.statcan.gc.ca/ census-recensement/2016/dp-pd/hlt-fst/pd-pl/Table.cfm?Lang= Eng\&T $=703 \& S R=1 \& S=87 \& O=A \& R P P=25 \& P R=59 \& C M A=0 \& C S D=0 \#$ map-popup

2 Supply, distribution and migration of physicians in Canada 2018: data tables Ottawa: Canadian Institue for health information, 2018.
Available: http://indicatorlibrary.cihi.ca/display/HSPIL/Proportion+of+ Physicians+in+Rural+Areas

3 Hanlon N, Halseth G. The greying of resource communities in northern British Columbia. Can Geogr 2005;49:24.

4 World Health Organisation. Declaration of Alma-Ata International Conference on primary health care; Alma-Ata USSR, 1978.

5 Teja B, Daniel I, Pink GH, et al. Ensuring adequate capital investment in Canadian health care. CMAJ 2020;192:E677-83.

6 Sullivan L, Ryser L, Halseth G. Recognizing rural: the new rural economy and towards a new model of rural service. J Rural Community Dev 2014;9:219-45.

7 Hanlon N, Macleod ML, Reay T. Partnering for Health Care Sustainability in Smaller Urban Centres: Why and How a Health Authority Chose to 'Go Upstream'. In: Halseth G, Markey S, Ryser L, eds. Service provision and rural sustainability. 1 edn. New York: Routledge, 2018: 80-95.

$8 \mathrm{Nel} \mathrm{E}$, Connelly S. Rural health service delivery challenges in an era of neoliberalism in New Zealand. In: Halseth G, Markey S, Ryser L, eds. Service provision and rural sustainability. New York: Routledge, 2019: 65-79.

9 Mahmud S. Citizen participation in the health sector in rural Bangladesh. IDS Bulletin 2004;35:7.

10 Nimegeer A, Farmer J, Munoz SA, et al. Community participation for rural healthcare design: description and critique of a method. Health Soc Care Community 2016;24:175-83.

11 Petersen I, Baillie K, Bhana A, et al. Understanding the benefits and challenges of community engagement in the development of community mental health services for common mental disorders: lessons from a case study in a rural South African subdistrict site. Transcult Psychiatry 2012;49:418-37.

12 Farmer J, Philip L, King G, et al. Territorial tensions: misaligned management and community perspectives on health services for older people in remote rural areas. Health Place 2010;16:275-83.

13 Davy C, Cass A, Brady J, et al. Facilitating engagement through strong relationships between primary healthcare and Aboriginal and Torres Strait Islander peoples. Aust N Z J Public Health 2016;40:535-41.

14 Kenny A, Hyett N, Sawtell J, et al. Community participation in rural health: a scoping review. BMC Health Serv Res 2013;13:64.

15 MacLeod MLP, Hanlon N, Reay T, et al. Partnering for change. $J$ Health Organ Manag 2019;34:255-72.

16 Farmer J, Nimegeer A. Community participation to design rural primary healthcare services. BMC Health Serv Res 2014;14:130.

17 Hammanyero Kl, Bawa S, Braka F, et al. Lessons learnt from implementing community engagement interventions in mobile hardto-reach (hTR) projects in Nigeria, 2014-2015. BMC Public Health 2018:18:1306.

18 Farmer J, Taylor J, Stewart E, et al. Citizen participation in health services co-production: a roadmap for navigating participation types and outcomes. Aust J Prim Health 2017;23:509-15.

19 Farmer J, Currie M, Kenny A, et al. An exploration of the longer-term impacts of community participation in rural health services design. Soc Sci Med 2015;141:64-71.

20 Boelen C. Towards unity for health: challenges and opportunities for partnerships in health development. Geneva, Switzerland: World Health Organisation, WHO/EIP/OSD/, 2000: 9. 2000.

21 Patton MQ. Qualitative evaluation and research methods: integrating theory and practice. 4 edn. Thousand Oaks, California: Sage, 2015.

22 Carter CA, Ruhe MC, Weyer S, et al. An appreciative inquiry approach to practice improvement and transformative change in health care settings. Qual Manag Health Care 2007;16:194-204.

23 Whitney D, Trosten-Bloom A. The power of Appreciative enquiry: a practical guide to positive change. 2 edn. San Francisco: BerrettKoehler, 2010.

24 Snadden D, Reay T, Hanlon N, et al. Engaging primary care physicians in system change - an interpretive qualitative study in a remote and rural health region in Northern British Columbia, Canada. BMJ Open 2019;9:e028395.

25 Best A, Greenhalgh T, Lewis S, et al. Large-system transformation in health care: a realist review. Milbank Q 2012;90:421-56.

26 Greenhalgh T, Papoutsi C. Studying complexity in health services research: desperately seeking an overdue paradigm shift. BMC Med 2018;16:95. 